\title{
Hepatitis C infection in patients with hereditary bleeding disorders: epidemiology, natural history, and management
}

\author{
Nikolaos Papadopoulos ${ }^{a}$, Vasiliki Argiana ${ }^{a}$, Melanie Deutsch ${ }^{b}$
}

417 Army Share Fund Hospital of Athens; Hippokration General Hospital of Athens, Medical School of National \& Kapodistrian University of Athens, Greece

Abstract

\section{Introduction}

Chronic hepatitis $\mathrm{C}(\mathrm{CHC})$ is a common global public health problem [1]. In 2015, 71 million individuals were infected with hepatitis $\mathrm{C}$ virus (HCV) worldwide [2]. Although the prevalence of $\mathrm{HCV}$ infection has decreased in developed countries as a result of effective prevention plans, it remains high in developing countries $[3,4]$. HCV is the main cause of liver diseases in both developed and developing countries, leading to an increased risk of liver failure and hepatocellular

${ }^{\mathrm{a}} \mathrm{s}^{\mathrm{st}}$ Department of Internal Medicine, 417 Army Share Fund Hospital of Athens (Nikolaos Papadopoulos, Vasiliki Argiana); ${ }^{\text {b }}{ }^{\text {nd }}$ Department of Internal Medicine, Hippokration General Hospital of Athens, Medical School of National \& Kapodistrian University of Athens (Melanie Deutsch), Greece

Conflict of Interest: None

Correspondence to: Nikolaos Papadopoulos, Monis Petraki 10-12, 11521 Athens, Greece, e-mail: nipapmed@gmail.com

Received 10 July 2017; accepted 20 September 2017; published online 26 October 2017

DOI: https://doi.org/10.20524/aog.2017.0204 carcinoma (HCC) worldwide [3,5]. In Europe, HCV is nowadays responsible for the vast majority (70\%) of all chronic hepatitis cases and HCCs (60\%), while it is also responsible for $40 \%$ of all liver cirrhosis cases and 30\% of infections in liver transplants [6]. Today, the major cause of HCV infections is parenteral drug use. However, in the 1970s and 1980s, before the implementation of effective and universal screening of blood and blood-derived clotting factors, most patients with hereditary bleeding disorders who received transfusions were infected.

Hereditary bleeding disorders include a group of diseases with abnormalities of coagulation. The most frequently encountered hereditary bleeding disorders include von Willebrand's disease and hemophilia A and B. Hemophilia is the best known hereditary bleeding disorder and is estimated to affect 1-5 individuals per 50,000 male population [7]. Prior to 1990, almost all patients acquired HCV infection; moreover, some of them were also coinfected with human immunodeficiency virus (HIV). Rates of disease progression among patients with congenital bleeding disorders and chronic HCV infection vary; however, the time of infection and coinfection with HIV appear to correlate with more rapid progression [8]. Antiviral treatment is no different from that of other infected individuals and aims to eradicate HCV and improve liver fibrosis [9]. 
In this article, we aimed to review comprehensively the data regarding the epidemiology, natural history and especially the management and treatment of $\mathrm{HCV}$ infection in patients with hereditary bleeding disorders.

\section{Epidemiology}

Prior to the widespread development of viral inactivation of coagulation factor concentrates in the mid-1980s, followed by universal screening, infection with HCV was virtually inevitable in patients who received pooled plasma products as a treatment for hereditary bleeding disorders, such as hemophilia [10,11]. In 1993 the observed prevalence of hemophilia in Greece was 14 per 100,000 males. However, the prevalence at birth was 23.1 per 100,000 male births, $65 \%$ higher than the observed prevalence, mainly because of the presence of unregistered or misdiagnosed patients and deaths due to HIV [12]. CHC has been reported not only in patients who were treated with plasma-derived factor concentrate, but also in patients who received cryoprecipitate and fresh-frozen plasma [13]. Since only $20 \%$ of patients infected with HCV clear the infection naturally, $\mathrm{CHC}$ represents a significant health problem in this group of patients [14].

Several studies have recorded data about the epidemiology of HCV infection worldwide. In general, depending on the laboratory methods used (anti-HCV positivity or viremia status) and the time the data were presented, the prevalence of HCV infection has a marked geographical variation [15]. In Scotland, according to the NHS, the total number of patients with bleeding disorders, infected with $\mathrm{HCV}$ as a result of receiving pooled plasma products administered between 1970 and 1989 , is estimated at 455 . Of these, 255 had a documented positive anti-HCV test, while 200 were assessed as probably infected [16]. In a study from Bosnia, HCV infection was positive in $38.7 \%$ of cases of hemophilia, while it was found $68 \%$ in the Netherlands and $44.3 \%$ in Greece [17-19]. By $1993,89 \%$ of hemophiliacs in the United States were infected with $\mathrm{HCV}$ from exposure to contaminated clotting factor concentrates [20]. In a meta-analysis of the prevalence of HCV in countries under the Eastern Mediterranean Region Office (EMRO) of the World Health Organization, the researchers concluded that most EMRO countries fail to report the precise number of hemophilic patients, which varies from 1 per 100,000 male population in Saudi Arabia and Pakistan to 15.8 per 100,000 male population in Qatar [21]. The seroprevalence of anti-HCV positivity among hemophilic patients in Iran varies from $15.6-76.7 \%$ and was estimated to be $40.8 \%$ in a meta-analysis [22]. In another study conducted in Korea, anti-HCV positivity in 1999 was reported to be $49.1 \%$ and $47.9 \%$ for hemophilia A and B, respectively, while it decreased to $40.1 \%$ and $34.1 \%$ in 2005 , and $33 \%$ and $23.8 \%$ in 2012 , respectively [23] (Fig. 1).

In general, the genotype distribution in the $\mathrm{HCV}$ population has a wide ethnic and geographical variation. Therefore, in patients with hemophilia the genotype distribution usually reflects the genotypes of the respective blood donor population. One important characteristic in this group of patients is that a significant proportion has a mixed-genotype infection due to multiple exposures to contaminated blood products over a period of years [24]. Overall, HCV genotype 1 seems to be the dominant one (Iran $72.7 \%$, Australia 65\%, USA $46.2 \%)$ followed by genotype 3 (27.3\%, $30 \%$ and $42 \%$ respectively) [25-27].

In this context, interesting early data regarding genotype distribution were provided by the Multicenter Hemophilia Cohort Study in 1998. Genotyping was performed in 109 blood samples collected during follow up (about 10 years) from 32 hemophilic patients (17 HIV-positive and 15 HIV-negative). In $58 \%$ of the patients, multiple changes of the genotype were observed during follow up and were significantly more frequent in the HIV-positive (76\%) than in the HIV-negative (33\%)patients [26].

\section{Natural history}

CHC progresses slowly, but after about two decades of chronic infection end-stage liver disease (ESLD) may occur in $10-20 \%$ of patients [28-30]. It seems that the progression to ESLD in patients with inherited bleeding disorders is similar to that in HCV-positive individuals in the general population. Despite this fact, the overall mortality of patients with hemophilia was found to be from two to five times higher than that of the general population [31]. Moreover, other researchers reported an extremely high mortality due to HCV, namely 16 times higher, in patients with hemophilia compared with the general population, mainly from the development of liver cirrhosis and HCC [32]. After 12-25 years of infection, reported incidences of ESLD vary, depending mainly on the criteria used for the definition of cirrhosis (liver biopsy or noninvasive techniques like liver elastography) $[33,34]$. In some series, up to $30 \%$ of patients with bleeding disorders developed long-term complications of chronic HCV infection and liver failure was documented as being the commonest cause of death in these patients [35]. Coinfection with HIV, duration of $\mathrm{HCV}$ infection and barriers to $\mathrm{HCV}$ treatment seem to represent the most important factors that have been associated with ESLD in these patients [36]. In general, coinfection with HIV had a negative influence on the natural course of the hepatic disease. Early studies have shown that HCV RNA levels were significantly higher in HIV-positive than in HIV-negative patients with hemophilia [37].

In addition, coinfection with HIV was found to be associated with an increased rate of progression of chronic $\mathrm{HCV}$ to cirrhosis [38]. In one study, carried out 10 years ago, the cumulative incidence of ESLD ranged from $12 \%$ in HIVnegative patients to $35 \%$ in patients coinfected with HIV [39]. Likewise, an early Greek study followed 138 hemophiliacs with $\mathrm{HCV}$ infection for 28 years to determine the factors that influence the natural history of the liver disease in these patients: $19 \%$ of the patients developed cirrhosis and $9 \%$ liver failure, with HIV positivity being one of the major risk factors independently associated with a worse outcome [40]. 


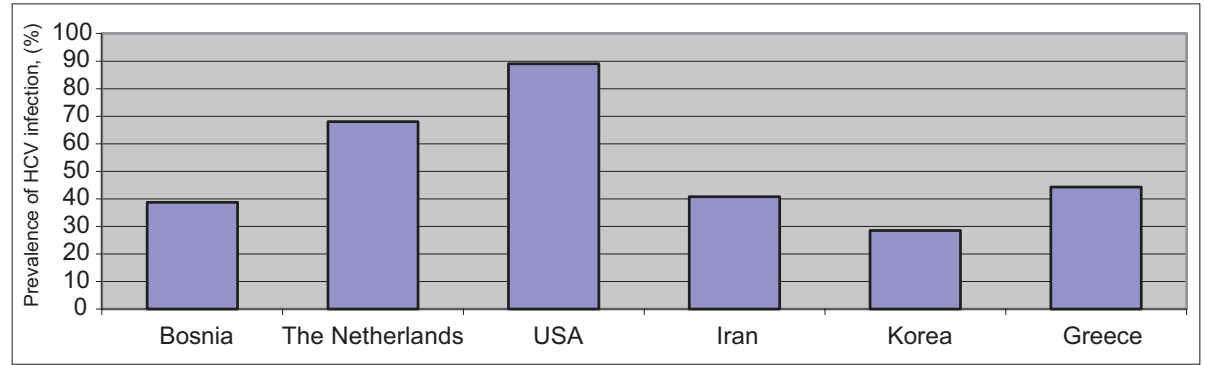

Figure 1 Geographical variation of hepatitis $\mathrm{C}$ virus infection among patients with hereditary blood disorders

However, as highly active antiretroviral therapy has dramatically improved the course of HIV infection, HCVrelated liver disease has emerged as the leading cause of mortality in HCV/HIV-coinfected patients and is one of the most common causes of death in such patients with hemophilia $A$ and B [41]. The duration of the HCV infection has also been strongly associated with an increased risk of ESLD. As most of these patients acquired their HCV infection in the early years of life, hazard rates for ESLD increased from 0.10 in the first decade of infection to 0.90 after more than 20 years of infection [39].

Another risk factor for the more rapid progression of liver disease was found to be represented by the genotype 1 $\mathrm{HCV}$ infection. In one study from Italy, in a cohort of 88 $\mathrm{HCV}$-positive HIV-negative hemophilia patients followed for 25 years, 6 patients ( 4 with genotype 1) developed cirrhosis and 4 patients (all genotype 1) developed liver failure [28]. Furthermore, the presence of genotype $1 \mathrm{HCV}$ infection (hazard ratio 2.2, 95\% confidence interval [CI] 1.1-4.2) and alcohol abuse (hazard ratio 4.9, 95\%CI 2.5-9.6) were also associated with a higher risk of ESLD [39].

\section{Management}

The results of treatment with interferon (IFN)-based therapies in HIV-negative and treatment naïve patients appear to be similar to those in the general population, with an overall sustained virological response (SVR) rate of 50-60\% [42]. However, data regarding the treatment response rate in the subgroup of HIV-positive and treatment-experienced patients are very limited $[43,44]$. Although treatment has been offered to patients with bleeding disorders, many of them have declined IFN-based therapy, mainly because of the expected side effects [18]. Side effects were common and the frequency of dose reduction or discontinuation of antiviral therapy was a common problem among studies with IFN-based therapies [45]. Nowadays, direct-acting antivirals (DAAs) have changed the landscape of HCV treatment. Although clinical data for patients with hereditary blood disorders are still limited, DAA therapy appears to be highly effective, safe and well tolerated [46-51]. The antiviral treatment of $\mathrm{CHC}$ in patients with hereditary bleeding disorders is not different from that of any other infected patients and should follow recently published guidelines, such as those proposed by the European Association for the Study of the Liver (EASL) [9,52].

\section{IFN-based therapies}

(Peg)IFN-based treatment was the standard of care for many years in HCV treatment [53-55]. Several studies have examined the effect of combination therapy with PegIFN plus ribavirin (RBV) in patients infected with HCV. A review of 35 studies that included 1151 patients with hemophilia revealed that combination therapy with RBV is superior to IFN monotherapy, with reported responses in the hemophilia population being similar to those seen in the general population: $10-20 \%$ for IFN monotherapy, $30-40 \%$ for IFN plus RBV, and $50-60 \%$ for PegIFN plus RBV $[53,56]$. However, the majority of patients included in these studies were treatment-naïve and HIV-negative. This selective population could explain the contrast with previous reports suggesting that patients with hemophilia might have a worse response to antiviral therapy [57]. The first meta-analysis performed in $\mathrm{HCV}$-infected hemophiliac patients confirmed that the combination of PegIFN plus RBV was superior compared with the combination of IFN plus RBV (SVR rates $61 \%$ vs. $43 \%$ ), though this difference was not statistically significant by metaregression. Moreover, the relationship between SVR and type of IFN used, at least for non-1 genotypes, was not clear [58].

On the other hand, many patients with inherited bleeding disorders were resistant to start treatment with PegIFN plus RBV, mainly because of side effects and relatively low SVR rates, especially for HCV genotype 1, the most prevalent in this population. The most frequently reported side effects of IFN-based treatment are fatigue, headache, influenza-like symptoms, hematological abnormalities and neuropsychiatric symptoms $[53,59]$.

In a recent study, investigators assessed the occurrence of side effects and the changes in quality of life during antiviral treatment with PegIFN and RBV in patients with inherited bleeding disorders and CHC [60]. Irritability was reported in more than $10 \%$ of patients, while all patients reported fatigue during treatment. Other frequently reported side effects were headache (94\%), pruritus and skin rash (94\%), cerebral dysfunction (such as concentration problems) (89\%), decreased appetite (89\%), fever (85\%), hair loss (85\%) and sleeping problems $(83 \%)$. Most of these side effects started during the first week of IFN-based treatment, while within four weeks after cessation of treatment most of the side effects had ameliorated. However, fatigue, pruritus and skin rash, concentration and sleeping problems were still present in a large number of patients (59\%, 42\%, 39\% and 34\%, respectively). Other reported side effects were dyspnea (43\%), cough (21\%), dry mouth and 
thirst (19\%), dry and painful eyes (13\%), changes in sensation of taste $(11 \%)$, and memory loss (9\%). Two patients stopped treatment prematurely due to side effects.

The most usual neuropsychiatric symptom during treatment with PegIFN plus RBV is depression. The pathogenesis through which IFN- $\alpha$ induces depression is largely unknown. However, IFN seems to have a direct effect on different cerebral processes. Downregulation of the glucocorticoid receptor, which is an important component of the negative feedback system of the hypothalamic-pituitary-adrenal axis, and of serotonin receptor $1 \mathrm{~A}$ (5-HTR1A) is suggested to play an important role [61]. In addition, an increase in the transcription and uptake activity of serotonin transporters may also induce depression [62]. Changes in the levels of certain cytokines, such as increased levels of interleukin (IL)-6 and IL-8, may be associated with depression during IFN-based treatment [63]. The opioid and the noradrenaline system may also be involved in depression symptoms during IFN-based treatment, while RBV is reported to enhance this phenomenon [64-65]. Drug-induced depression might enhance the psychosocial problems in this group of patients. A prospective study assessed the occurrence, course, treatment and risk factors of depression during antiviral treatment for $\mathrm{CHC}$ in patients with inherited bleeding disorders [66]. Forty-seven patients were included in the study. At baseline, 42 patients had no depression. Finally, 23 (55\%) developed depression during antiviral treatment and in the majority (78\%) during the first 12 weeks.

\section{Treatment with DAAs}

In recent years $\mathrm{HCV}$ treatment has been undergoing a major revolution. Multiple orally administrated DAAs have been approved for HCV treatment. According to the action mechanism and the therapeutic target, four classes of DAAs have been defined: nonstructural (NS) proteins 3/4A protease inhibitors, including simeprevir, paritaprevir and grazoprevir (GZR); NS5B nucleoside polymerase inhibitors, including sofosbuvir (SOF); NS5B non-nucleoside polymerase inhibitors, including dasabuvir; and NS5A inhibitors, including ombitasvir, ledipasvir (LDV), daclatasvir (DCV), elbasvir (EBR), and velpatasvir [67]. The major studies with DAAs did not include patients with special comorbidities, while real-life studies also lack significant data for patients with inherited hemorrhagic disorders and HCV or HCV/HIV infections. Therefore, until recently, there was not much experience from treating these patients with DAAs [68].

One of the most popular combinations used in the treatment of HCV infection is the fixed-dose combination of SOF/LDV. In phase III studies including patients from the general population with genotype $1 \mathrm{HCV}$ infection, LDV/SOF combination for 8-12 weeks achieved rates of SVR 12 weeks post therapy (SVR12) $>90 \%$ with only few adverse effects [46]. A study was conducted to explore the efficacy and safety of a fixed-dose combination of SOF/LDV plus RBV in patients with $\mathrm{CHC}$ and inherited bleeding disorders: fourteen patients with inherited bleeding disorders infected by genotype 1 were enrolled. All of them experienced rapid viral suppression after initiating treatment and all of them (100\%, 95\%CI 77-100\%) achieved both SVR4 and SVR12. No patient experienced virological failure during treatment and no patient experienced virological relapse. Overall, 13 patients (93\%) experienced at least one adverse event during treatment. The most common adverse events were fatigue, headache, nausea and insomnia [47]. The fixed SOF/ LDV combination for 12 weeks was further evaluated in 69 HCV genotype 1 patients and in one genotype 4 patient with inherited bleeding disorders (HIV-positive 19\%, cirrhosis 28\%) with an overall SVR12 of 99\% [48]. Five difficult-to-treat HCV genotype 1a patients (treatment experienced with cirrhosis) were also included and were treated with the same combination for 24 weeks with an overall SVR12 of 100\%. A small number of HCV genotype 2 and 3 patients were also enrolled in this well designed study. Ten HCV genotype 2 (HIV-positive 40\%, cirrhosis 20\%, treatment-experienced 30\%) patients were treated with SOF plus RBV for 12 weeks with an overall SVR12 of $100 \%$, and six HCV genotype 3 (HIV-positive $50 \%$, cirrhosis $33 \%$, treatment experienced $17 \%$ ) patients were treated with SOF/RBV for 24 weeks with an overall SVR of $83 \%$. The high efficacy of SOF/LDV therapy was further documented in a study by Nagao and Hanabusa: 43 patients with hemophilia and HCV genotype 1/4 infection (HIV-positive 75\%) were treated with SOF/LDV for 12 weeks with an overall SVR12 of 95\% [49]. Furthermore, the efficacy did not differ significantly between the HIV-negative and HIV-positive patients (SVR12: 100\% in HIV-negative and 95\% in HIV-positive, $\mathrm{P}=0.12$ ).

The efficacy of the SOF/DCV combination has only been evaluated in two HCV genotype 1a patients with hemophilia and non-compensated cirrhosis, who achieved SVR12 after a course of 24-week duration [50].

Finally, a randomized placebo-controlled phase III study (C-EDGE IBLD) was conducted to determine the safety and efficacy of EBR $50 \mathrm{mg}$ /day plus the protease inhibitor GZR $100 \mathrm{mg} /$ day as a fixed combination for 12 weeks in patients with inherited bleeding disorders and HCV genotype 1 or 4 infection [51]. Overall, 107 patients were enrolled (including patients with sickle-cell disease and thalassemia) in the EBR/GZR arm: SVR12 was $93.5 \%$, while virological relapse was $5.6 \%$. The SVR rate was as high as $100 \%$ even in difficult-to-treat subgroups, such as treatment-experienced and/or cirrhotic patients. However, the presence of baseline NS5A resistance-associated substitutions (RASs) among patients with genotype 1a infection had a dramatic impact on SVR rate, which could be as low as $25 \%$. Moreover, in this study, lower response rates were recorded in patients with hemophilia A/B or von Willebrand disease (89.4\%) than in patients with sickle-cell disease $(94.7 \%)$ or $\beta$-thalassemia (97.6\%). This finding is most likely to be attributable to the presence of baseline NS5A RASs in most of these patients (4/6 patients who experienced virological relapse suffered from hemophilia A/B or von Willebrand disease, while $3 / 4$ of them had baseline RASs). The safety profile in patients receiving EBR/GZR was similar to that in those receiving placebo. The most frequent side effects were headache, fatigue, nausea, and asthenia, but there were no discontinuations. All available studies of DAAs in inherited bleeding disorders, including patients' characteristics and SVR rates, are shown in Table 1. 
Hepatitis $\mathrm{C}$ and hereditary bleeding disorders $\mathbf{5}$

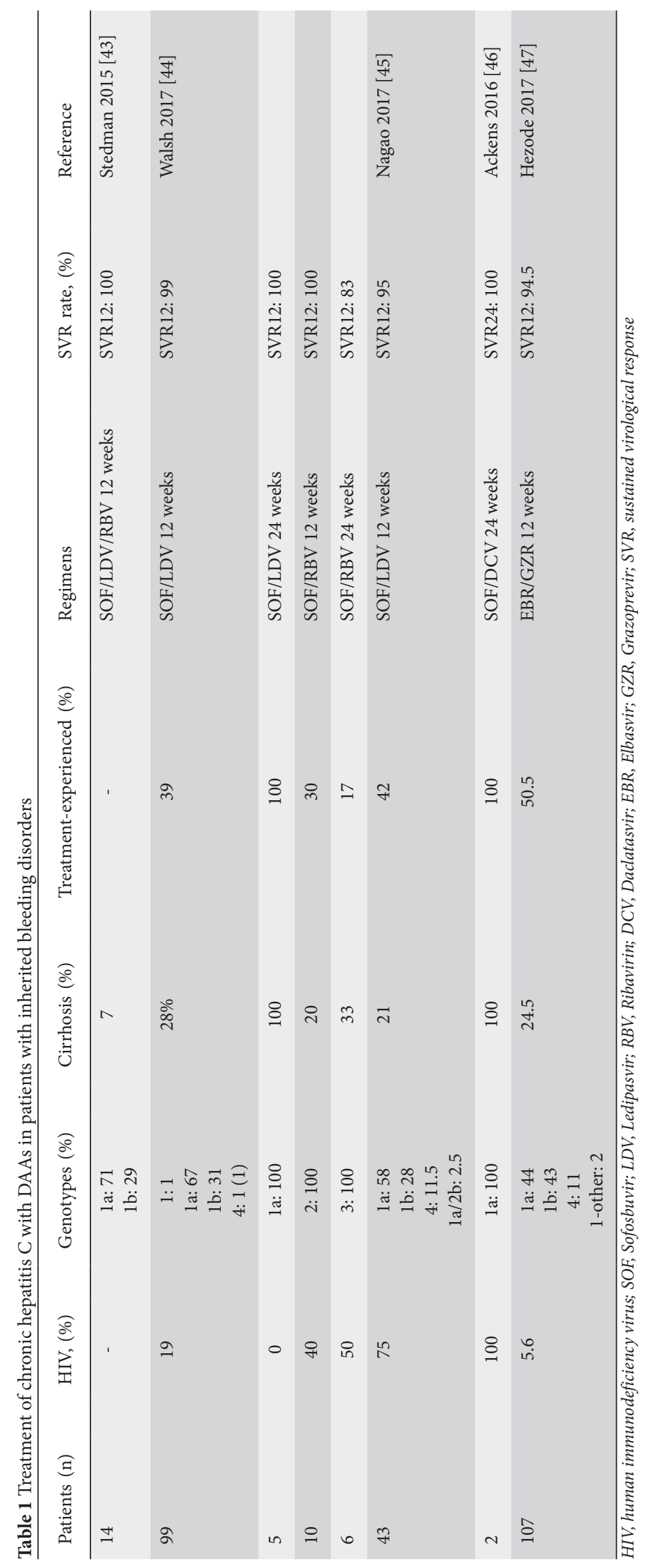




\section{Concluding remarks}

Improvements in blood-banking procedures have led to almost no new cases of transfusion-associated HCV infections among patients with hereditary bleeding disorders. However, a high proportion of these patients still suffer from $\mathrm{CHC}$, which may lead to liver cirrhosis. In the past, patients with HIV/ $\mathrm{HCV}$ coinfection represented a difficult group of patients with a more rapid progression of their liver disease. The "classic" IFN-based treatment was the standard of care for many years and seemed to be as efficient as in the general population. Nowadays, DAAs are the standard of care in HCV treatment. Although these agents are very effective and well tolerated, clinical data for these patients are limited. However, it seems that treatment is similar to that in the general population, while DAAs are applicable to patients with hereditary bleeding disorders and $\mathrm{CHC}$ according to recently published EASL guidelines [9]. Moreover, $\mathrm{HIV} / \mathrm{HCV}$ coinfected patients are no longer a "difficult-to-treat" group in the era of DAAs.

\section{References}

1. Mohamed AA, Elbedewy TA, El-Serafy M, El-Toukhy N, Ahmed W, Ali El Din Z. Hepatitis C virus: a global view. World J Hepatol 2015;7:2676-2680.

2. Polaris Observatory HCV Collaborators. Global prevalence and genotype distribution of hepatitis C virus infection in 2015: a modelling study. Lancet Gastroenterol Hepatol 2017;2:161-176.

3. Alter MJ. Epidemiology of hepatitis C virus infection. World $J$ Gastroenterol 2007;13:2436-2441.

4. Alavian SM, Fallahian F. Comparison of seroepidemiology and transmission modes of viral hepatitis $\mathrm{C}$ in Iran and Pakistan. Hepat Mon 2008;8:51-59.

5. Alavian SM. Hepatitis $\mathrm{C}$ virus infection: epidemiology, risk factors and prevention strategies in public health in I.R. Iran. Gastroenterol Hepatol Bed Bench 2010;3:5-14.

6. Ahmadipour MH, Alavian SM, Amini S, Azadmanesh K. Hepatitis C virus genotypes. Hepat Mon 2005;5:77.

7. Tonbary YA, Elashry R, Zaki MS. Descriptive epidemiology of hemophilia and other coagulation disorders in Mansoura, Egypt: retrospective analysis. Mediterr J Hematol Infect Dis 2010;2:e2010025.

8. Kucharska M, Zaleska-Dorobisz U, Szymczak A, et al. Stage of liver fibrosis in patients with congenital bleeding disorders and infected with hepatitis C virus. Pol Arch Intern Med 2017;127:412-417.

9. European Association for the Study of the Liver. Electronic address: easloffice@easloffice.eu. EASL Recommendations on Treatment of Hepatitis C 2016. J Hepatol 2017;66:153-194.

10. Laurian Y, Blanc A, Delaney SR, Allain JP. All exposed hemophiliacs have markers of HCV. Vox Sang 1992;62:55-56.

11. Watson HG, Ludlam CA, Rebus S, Zhang LQ, Peutherer JF, Simmonds P. Use of several second generation serological assays to determine the true prevalence of hepatitis $\mathrm{C}$ virus infection in haemophiliacs treated with non-virus inactivated factor VIII and IX concentrates. Br J Haematol 1992;80:514-518.

12. Koumbarelis E, Rosendaal FR, Gialeraki A, et al. Epidemiology of haemophilia in Greece: an overview. Thromb Haemost 1994;72:808-813.

13. Wilde JT, Mutimer D, Dolan G, et al. UKHCDO guidelines on the management of $\mathrm{HCV}$ in patients with hereditary bleeding disorders 2011. Haemophilia 2011;17:e877-e883.

14. Micallef JM, Kaldor JM, Dore GJ. Spontaneous viral clearance following acute hepatitis $\mathrm{C}$ infection: a systematic review of longitudinal studies. J Viral Hepat 2006;13:34-41.

15. Mohd Hanafiah K, Groeger J, Flaxman AD, Wiersma ST. Global epidemiology of hepatitis C virus infection: new estimates of age-specific antibody to HCV seroprevalence. Hepatology 2013;57:1333-1342.

16. Khan MM, Tait RC, Kerr R, et al. Hepatitis C infection and outcomes in the Scottish haemophilia population. Haemophilia 2013; 19:870-875.

17. Zhubi B, Mekaj Y, Baruti Z, Bunjaku I, Belegu M. Transfusiontransmitted infections in haemophilia patients. Bosn J Basic Med Sci 2009;9:271-277.

18. Posthouwer D, Plug I, van der Bom JG, Fischer K, Rosendaal FR, Mauser-Bunschoten EP. Hepatitis C infection among Dutch haemophilia patients: a nationwide cross-sectional study of prevalence and antiviral treatment. Haemophilia 2005;11:270-275.

19. Katsoulidou A, Sypsa V, Tassopoulos NC, et al. Molecular epidemiology of hepatitis C virus (HCV) in Greece: temporal trends in HCV genotype-specific incidence and molecular characterization of genotype 4 isolates. J Viral Hepat 2006;13:19-27.

20. Troisi CL, Hollinger FB, Hoots WK, et al. A multicenter study of viral hepatitis in a United States hemophilic population. Blood 1993;81:412-418.

21. Alavian SM, Aalaei-Andabili SH. Lack of knowledge about hepatiti $C$ infection rates among patients with inherited coagulation disorders in countries under the Eastern Mediterranean Region Office of WHO (EMRO): a meta-analysis. Hepat Mon 2012;12:244-252.

22. Alavian SM. Hepatitis C infection in Iran: a review article. Iran J Clin Infect Dis 2009;4:47-59.

23. Rou WS, Lee BS. Hepatitis C virus infection in patients with hemophilia in Korea: is antiviral therapy effective and safe? Clin Mol Hepatol 2015;21:122-1224.

24. Fujimura Y, Ishimoto S, Shimoyama T, et al. Genotypes and multiple infections with hepatitis $\mathrm{C}$ virus in patients with haemophilia $\mathrm{A}$ in Japan. J Viral Hepat 1996;3:79-84.

25. Samimi-Rad K, Shahbaz B. Hepatitis C virus genotypes among patients with thalassemia and inherited bleeding disorders in Markazi province, Iran. Haemophilia 2007;13:156-163.

26. Eyster ME, Sherman KE, Goedert JJ, Katsoulidou A, Hatzakis A. Prevalence and changes in hepatitis $\mathrm{C}$ virus genotypes among multitransfused persons with hemophilia. The Multicenter Hemophilia Cohort Study. J Infect Dis 1999;179:1062-1069.

27. Baker RI, Smith J, Eikelboom J, et al. Hepatitis C genotypes in Australian haemophilia patients. Aust N Z J Med 1996;26:789-792.

28. Franchini M, Rossetti G, Tagliaferri A, et al. The natural history of chronic hepatitis $\mathrm{C}$ in a cohort of HIV-negative Italian patients with hereditary bleeding disorders. Blood 2001;98:1836-1841.

29. Meijer K, Haagsma EB, Kok T, Schirm J, Smid WM, van der Meer J. Natural history of hepatitis C in HIV-negative patients with congenital coagulation disorders. J Hepatol 1999;31:400-406.

30. Yee TT, Griffioen A, Sabin CA, Dusheiko G, Lee CA. The natural history of HCV in a cohort of haemophilic patients infected between 1961 and 1985. Gut 2000;47:845-851.

31. Plug I, Van Der Bom JG, Peters M, et al. Mortality and causes of death in patients with hemophilia, 1992-2001: a prospective cohort study. J Thromb Haemost 2006;4:510-516.

32. Darby SC, Ewart DW, Giangrande PL, et al. Mortality from liver cancer and liver disease in haemophilic men and boys in UK given blood products contaminated with hepatitis C. UK Haemophilia Centre Directors' Organisation. Lancet 1997;350:1425-1431.

33. Maor Y, Halfon P, Bashari D, et al. Fibrotest or Fibroscan for evaluation of liver fibrosis in haemophilia patients infected with 
hepatitis C. Haemophilia 2010;16:148-154.

34. Posthouwer D, Mauser-Bunschoten EP, Fischer K, van Erpecum KJ, de Knegt RJ. Significant liver damage in patients with bleeding disorders and chronic hepatitis C: non-invasive assessment of liver fibrosis using transient elastography. J Thromb Haemost 2007;5:25-30.

35. Poynard T, Bedossa P, Opolon P. Natural history of liver fibrosis progression in patients with chronic hepatitis C. The OBSVIRC, METAVIR, CLINIVIR, and DOSVIRC groups. Lancet 1997;349:825-832.

36. Minola E, Prati D, Suter F, et al. Age at infection affects the longterm outcome of transfusion-associated chronic hepatitis C. Blood 2002;99:4588-4591.

37. Eyster ME, Fried MW, Di Bisceglie AM, Goedert JJ. Increasing hepatitis C virus RNA levels in hemophiliacs: relationship to human immunodeficiency virus infection and liver disease. Multicenter Hemophilia Cohort Study. Blood 1994;84:1020-1023.

38. Bica I, McGovern B, Dhar R, et al. Increasing mortality due to endstage liver disease in patients with human immunodeficiency virus infection. Clin Infect Dis 2001;32:492-497.

39. Posthouwer D, Makris M, Yee TT, et al. Progression to end-stage liver disease in patients with inherited bleeding disorders and hepatitis C: an international, multicenter cohort study. Blood 2007; 109:3667-3671.

40. Makris M, Preston FE, Rosendaal FR, Underwood JC, Rice KM, Triger DR. The natural history of chronic hepatitis $C$ in haemophiliacs. Br J Haematol 1996;94:746-752.

41. Darby SC, Kan SW, Spooner RJ, et al. Mortality rates, life expectancy, and causes of death in people with hemophilia A or B in the United Kingdom who were not infected with HIV. Blood 2007; 110:815-825.

42. Posthouwer D, Mauser-Bunschoten EP, Fischer K, Makris M. Treatment of chronic hepatitis $C$ in patients with haemophilia: a review of the literature. Haemophilia 2006;12:473-478.

43. Sauleda S, Juárez A, Esteban JI, et al. Interferon and ribavirin combination therapy for chronic hepatitis $\mathrm{C}$ in human immunodeficiency virus-infected patients with congenital coagulation disorders. Hepatology 2001;34:1035-1040.

44. Hanabusa H. Efficacy of induction therapy with high-dose interferon for patients with hemophilia and human immunodeficiency virushepatitis C virus coinfection. Clin Infect Dis 2002;35:1527-1533.

45. Posthouwer D, Yee TT, Makris M, et al. Antiviral therapy for chronic hepatitis $\mathrm{C}$ in patients with inherited bleeding disorders: an international, multicenter cohort study. J Thromb Haemost 2007;5:1624-1629.

46. Afdhal N, Zeuzem S, Kwo P, et al; ION-1 Investigators. Ledipasvir and sofosbuvir for untreated HCV genotype 1 infection. $N$ Engl $J$ Med 2014;370:1889-1898.

47. Stedman CA, Hyland RH, Ding X, Pang PS, McHutchison JG, Gane EJ. Once daily ledipasvir/sofosbuvir fixed-dose combination with ribavirin in patients with inherited bleeding disorders and hepatitis C genotype 1 infection. Haemophilia 2016;22:214-217.

48. Walsh CE, Workowski K, Terrault NA, et al. Ledipasvir-sofosbuvir and sofosbuvir plus ribavirin in patients with chronic hepatitis $\mathrm{C}$ and bleeding disorders. Haemophilia 2017;23:198-206.

49. Nagao A, Hanabusa H. Brief report: The impact of ledipasvir/ sofosbuvir on HIV-positive and HIV-negative Japanese hemophilia patients with 1, 4, and mixed-genotype HCV. J Acquir Immune Defic Syndr 2017;74:418-422.

50. Ackens R, Posthouwer D. Treatment of chronic hepatitis C with direct acting antiviral agents in patients with haemophilia, end-stage liver disease and coinfected with HIV. Haemophilia 2016;22:e223-e225.

51. Hézode C, Colombo M, Bourlière M, et al. Elbasvir/Grazoprevir for patients with hepatitis $C$ virus infection and inherited blood disorders: a phase III study. Hepatology 2017p;66:736-745.

52. Giangrande PLF, Peyvandi F, O’Mahony B, et al. Kreuth IV: European consensus proposals for treatment of haemophilia with coagulation factor concentrates. Haemophilia 2017;23:370-375.

53. Manns MP, McHutchison JG, Gordon SC, et al. Peginterferon alfa$2 \mathrm{~b}$ plus ribavirin compared with interferon alfa- $2 \mathrm{~b}$ plus ribavirin for initial treatment of chronic hepatitis C: a randomised trial. Lancet 2001;358:958-965.

54. Krawitt EL, Ashikaga T, Gordon SR, Ferrentino N, Ray MA, Lidofsky SD; New York New England Study Team. Peginterferon alfa- $2 \mathrm{~b}$ and ribavirin for treatment-refractory chronic hepatitis $\mathrm{C}$. J Hepatol 2005;43:243-249.

55. Jacobson IM, Gonzalez SA, Ahmed F, et al. A randomized trial of pegylated interferon alpha-2b plus ribavirin in the retreatment of chronic hepatitis C. Am J Gastroenterol 2005;100:2453-2462.

56. Franchini M, Nicolini N, Capra F. Treatment of hepatitis C in hemophiliacs. Am J Hematol 2006;81:696-702.

57. Franchini M. Hepatitis C in haemophiliacs. Thromb Haemost 2004;92:1259-1268.

58. Franchini M, Mengoli C, Veneri D, Mazzi R, Lippi G, Cruciani M. Treatment of chronic hepatitis $\mathrm{C}$ in haemophilic patients with interferon and ribavirin: a meta-analysis. J Antimicrob Chemother 2008;61:1191-1200.

59. Fried MW, Shiffman ML, Reddy KR, et al. Peginterferon alfa-2a plus ribavirin for chronic hepatitis $\mathrm{C}$ virus infection. $N$ Engl J Med 2002;347:975-982.

60. Fransen van de Putte DE, Fischer K, Posthouwer D, MauserBunschoten EP. The burden of HCV treatment in patients with inherited bleeding disorders. Haemophilia 2011;17:791-799.

61. Cai W, Khaoustov VI, Xie Q, Pan T, Le W, Yoffe B. Interferon-alphainduced modulation of glucocorticoid and serotonin receptors as a mechanism of depression. J Hepatol 2005;42:880-887.

62. Bonaccorso S, Marino V, Puzella A, et al. Increased depressive ratings in patients with hepatitis $C$ receiving interferon-alphabased immunotherapy are related to interferon-alpha-induced changes in the serotonergic system. J Clin Psychopharmacol 2002;22:86-90.

63. Bonaccorso S, Puzella A, Marino V, et al. Immunotherapy with interferon-alpha in patients affected by chronic hepatitis $\mathrm{C}$ induces an intercorrelated stimulation of the cytokine network and an increase in depressive and anxiety symptoms. Psychiatry Res 2001; 105:45-55.

64. Loftis JM, Hauser P. The phenomenology and treatment of interferon-induced depression. J Affect Disord 2004;82:175-190.

65. Raison CL, Borisov AS, Broadwell SD, et al. Depression during pegylated interferon-alpha plus ribavirin therapy: prevalence and prediction. J Clin Psychiatry 2005;66:41-48.

66. Fransen Van De Putte DE, Fischer K, Posthouwer D, Van Erpecum K, Mauser-Bunschoten EP. Occurrence, course and risk factors of depression during antiviral treatment for chronic hepatitis $\mathrm{C}$ in patients with inherited bleeding disorders: a prospective study. Haemophilia 2009; 15:544-551.

67. Poordad F, Dieterich D. Treating hepatitis C: current standard of care and emerging direct-acting antiviral agents. J Viral Hepat 2012;19:449-464.

68. Witkop ML, Peerlinck K, Luxon BA. Medical co-morbidities of patients with haemophilia: pain, obesity and hepatitis C. Haemophilia 2016;22 (Suppl 5):47-53. 